\title{
Cosmologías, patrimonialización y eco-símbolos en el Pirineo catalán en un contexto global ${ }^{1}$
}

\section{Cosmologies, Heritagization and Eco-symbols in the Catalan Pyrinees within a Global Perspective}

\author{
Joan FRIGOLÉ \\ Departamento de Antropología cultural y social \\ Universitat de Barcelona \\ frigole@ub.edu
}

Recibido: 25 de octubre de 2011

Aceptado: 17 de febrero de 2012

\section{Resumen}

El texto analiza la relación entre diversas cosmologías, la patrimonialización de la cultura y la naturaleza y los eco-símbolos en un antiguo territorio campesino remodelado por la crisis de la economía campesina, la despoblación y el desarrollo de una economía terciaria. La creación de un parque natural, el progresivo asilvestramiento del paisaje y la presencia de nuevas categorías de población pusieron las condiciones para la coexistencia y también la tensión entre diferentes percepciones y prácticas relativas a la naturaleza. El texto distingue tres cosmologías estructuradas sobre diferentes concepciones de la naturaleza y su relación con la sociedad. Conjuntamente la patrimonialización de la naturaleza y la cosmología basada en la noción de biodiversidad generan eco-símbolos, que tienen una gran importancia para las empresas porque añaden valor a sus logos y marcas en un mercado global. Esta es una de las tres referencias que contextualizan la etnografía local.

Palabras clave: cosmología, patrimonialización, eco-símbolo, parque natural, asilvestramiento del paisaje.

\begin{abstract}
The paper analyses the relationship between diverse cosmologies, the heritagization of culture and nature and the eco-symbols in a former peasant territory reshaped by the collapse of peasant economy, the depopulation and the development of a service economy. The creation of a natural park, the progressive landscape's wilderness and the presence of new categories of people set the conditions for the coexistence of different perceptions and practices relative to nature. The paper distinguishes three cosmologies with different conceptions of nature and their relationship with society. Both the heritagization of nature and the cosmology based on the notion of biodiversity generate eco-symbols that have a great importance for enterprises
\end{abstract}

${ }^{1}$ Dedicado a la memoria de Ramón Valdés del Toro. Agradezco mucho la lectura y comentarios de Matilde Córdoba, Meritxell Sucarrat, Camila del Mármol y Ignasi Terradas. Con el soporte del proyecto de investigación del Ministerio de Educación y Ciencia, CSO2008-05065/ SOCI. 
as they add value to its logos and brands in a global market. This is one of the three global references that contextualize local ethnography.

Keywords: cosmology, heritagization, eco-symbol, natural park, landscape's wilderness.

Referencia normalizada: Frigolé, J. (2012) Cosmologías, patrimonialización y eco-símbolos en el Pirineo catalán en un contexto global. Revista de Antropología Social, 21: 173-196.

SUMARIO: 1. Introducción. 2. Cosmologías, patrimonialización y eco-símbolos. 3. Ecosímbolos y marcas en un mercado global. 4. Transformaciones en un valle Pirenaico: naturaleza salvaje y parque natural en un contexto global. 5. Consideraciones finales. 6. Referencias bibliográficas.

\section{Introducción}

Como introducción a la caracterización del objeto de estudio presento unas breves referencias etnográficas:

"Este no es un país de lobos" (Pastor de ovejas, 2010).

"Pienso que hemos perdido el norte. Estamos más preocupados por el asentamiento del lobo en el bosque que por el de las personas" (Ganadera, 2005).

"El lobo ha regresado a nuestro país" pero "no es un recién llegado. El futuro nos ofrece muchas oportunidades para hacer las cosas bien hechas y para integrar el lobo en nuestro paisaje como un compañero más, como el jabalí, el zorro, el quebrantahuesos, los abetos o las gencianas" (Jordi García Petit, director del Parque Natural del Cadí-Moixeró, en la revista del parque, El Picot negre, junio 2004).

"Seria realmente largo y extenso citar todos y cada uno de los actos de aprovechamiento indecente y escandaloso, que a lo largo de estos dieciséis años se han cometido por parte de los "lobos y sus clanes familiares" en detrimento de la justicia social y de la igualdad que predica la constitución" (Josep Badia, exalcalde, en la revista local, Flor del vent, 55, 2007).

De la visión de los que viven de la ganadería, a una imagen negativa aplicada a los políticos locales de derechas, y a otra positiva, construida por el director del parque mediante los términos integración y compañero. La distinción autóctono/ forastero es tan significativa para la población local como para el discurso global sobre biodiversidad. El director del parque es bien consciente de ello al negar que el lobo sea un recién llegado, es decir, un forastero, aunque proceda del norte de Italia.

Estas frases muestran una característica significativa del objeto de estudio: una pluralidad de puntos de vista y oposiciones existentes en una sociedad en relación a la naturaleza y a la política ambiental y cómo la naturaleza es convertida en diferentes tipos de símbolos. He elegido la polémica sobre el retorno/ reintroducción del lobo en el territorio no porque pretenda focalizar la atención sobre este animal, sino porque pone de manifiesto la complejidad del objeto de estudio, constituido por la relación entre tres concepciones de la naturaleza y un sistema social.

Los datos empíricos en los que se basa el análisis proceden de un trabajo de campo a tiempo parcial entre 2002 y 2010 en un valle del Pirineo catalán, que ha 
experimentado una gran transformación ecológica, económica y social en las últimas décadas. Mi trabajo de campo se ha ampliado a otras áreas próximas con el objetivo de recoger información sobre un parque natural creado el 1983, que incorpora partes de los territorios de 17 municipios, incluidos los dos del valle, y cuya extensión asciende a 41.060 has. Completaré estos datos con otros, referidos a otros territorios y al mundo global, para proporcionar un cierto contexto histórico, territorial y global al objeto de estudio.

Algunas precisiones sobre el término naturaleza. Según Descola (2005: 59), la naturaleza no existe como "un dominio ontológico autónomo" en las cosmologías que llama animismo y totemismo. El animismo incluye en un único dominio los seres humanos y los no humanos por medio de las nociones de persona, pariente y reciprocidad. El totemismo convierte las variantes de la alteridad no humana en referentes fundamentales para las especificidades humanas. La cosmología denominada naturalismo, en cambio, se basa en el dualismo naturaleza/sociedad y lleva aparejados la protección y el exterminio como los dos tipos básicos de relación entre humanos y no humanos. Escobar (1999: 6) relaciona la concepción de la naturaleza como una entidad real separada de la sociedad con el sistema capitalista que impuso "nuevas maneras de ver, racionalidad, gobernanza y mercantilización de la naturaleza." Diferencia tres regímenes de naturaleza, de acuerdo con la ilustración que ofrece: "el "orgánico" de las comunidades, el capitalista de las plantaciones y el tecnopaisaje de la biodiversidad y la biotecnología de los investigadores y de los empresarios" (ibid: 5). En cada uno de ellos, "los humanos están posicionados diferentemente, tienen diferentes conceptualizaciones, y hacen demandas diferenciadas sobre lo biológico" (ibid: 5). El peligro está en la reificación de las tipologías. En este sentido, Heyman (2004: 184) señala que no se trata de "contrastar arquetipos sino de verlos como temas que interaccionan en una situación dada." El reto es evitar quedar atrapado por una noción de "naturaleza abstracta" (Carrier, 2004: 5) en vez de "hablar de un lugar en términos de las experiencias de personas particulares que viven allí, (...) de las particularidades de las biografías y las relaciones sociales, memorias y valores, circunstancias y deseos de aquellas personas" (ibid: 4).

El objeto de estudio lo constituyen tres concepciones de la naturaleza y su relación mutua y sus relaciones con un único sistema social, basado en una economía dominante, la terciaria, que ha remodelado y reorientado elementos pertenecientes a sistemas productivos y estructuras sociales anteriores. El sistema social está integrado por diversos agentes sociales - campesinos, empresarios, turistas, neorurales y técnicos de la administración-, y sus relaciones mutuas. Para identificar las tres concepciones de la naturaleza y de la sociedad me he guiado por las distinciones y oposiciones tales como domesticado/salvaje, natural/artificial, y nativo/forastero, significativas para los agentes sociales y que codifican las características más destacadas de la relación entre naturaleza y sociedad. Las tres concepciones coexisten en el marco de una economía capitalista. Cada una de las concepciones mantiene relaciones de oposición total o parcial con las otras, conformando así una única estructura simbólica global. Los agentes sociales que integran el sistema socioeconómico se hallan enfrentados a clasificaciones, prácticas y poderes que chocan con su propio 
sistema de clasificación y amenazan su coherencia. Por medio de su identificación con un sistema de clasificación y el rechazo total o parcial de los otros sistemas de clasificación, los agentes sociales se representan a si mismos y representan a los otros. La propia concepción de la naturaleza y del territorio les permite reivindicar una posición y un protagonismo social. Las concepciones de la naturaleza implican a la vez concepciones de la sociedad y sus relaciones, ya que se determinan recíprocamente.

En un nivel más abstracto se podría caracterizar mi objeto de estudio como la relación entre un sistema cultural que articula tres sistemas de clasificación no coherentes entre si, jerarquizados, y un sistema social heterogéneo como resultado de las transformaciones económicas y de la remodelación que la economía terciaria ha impuesto a los sectores productivos y a los agentes sociales. La relación jerárquica entre los sistemas de clasificación es una réplica simbólica de las relaciones de poder existentes en el interior del sistema social, que incluye la sociedad local y las relaciones con los agentes que forman parte de un sistema social y político supra-local.

Mi perspectiva se inspira en una tradición que relaciona clasificaciones simbólicas y estructura social (Durkheim y Mauss, 1903; Douglas, 1978 y 1991; Descola, 2005).

Ofrezco a continuación una caracterización de las tres concepciones de la naturaleza, sobre el trasfondo de la transformación ecológica, económica y social del valle, su relación con la patrimonialización de la naturaleza y la creación de ecosímbolos y sus implicaciones para las marcas en un mercado global.

\section{Cosmologías, patrimonialización y eco-símbolos}

Una cosmología contiene categorías, principios y poderes (Douglas, 1978). Las categorías básicas que estructuran una cosmología condensan nociones específicas de significado, valor, orden, normalidad, poder, seguridad, inclusión, protección etc., y sus contrarios. Las cosmologías objeto de estudio se inscriben dentro del naturalismo (Descola, 2005), lo cual implica que adopten como presupuesto el dualismo naturaleza/sociedad, que hace posible la naturalización de seres sociales por medio de un lenguaje "natural", que comporta grados diversos de deshumanización, y el antropomorfismo de seres no humanos por medio de un lenguaje social y moral.

La primera cosmología se estructura en torno a la oposición domesticado/salvaje y se podría denominar campesina. En un sistema productivo que asociaba agricultura, ganadería ovina y silvicultura, la tierra de cultivo era un factor productivo muy importante y un referente de primer orden para la estratificación social, pero los prados y los bosques tenían también importancia. Los bosques podían retroceder con el avance de la tierra cultivada, pero no eran conceptualmente el extremo opuesto, un dominio salvaje, ya que producían "cosechas" sin siembra como setas, plantas medicinales, etc. La oposición cultivado/silvestre no equivale exactamente a la oposición domesticado: salvaje. La oposición fuerte entre domesticado y salvaje se manifiesta en relación a los animales que depredan los animales domésticos: aves de rapiña, mustélidos, lobos, serpientes, etc. La protección de los animales domésticos 
implicaba la erradicación o el exterminio de los salvajes. Cuando este orden material y simbólico formal se desintegró afloraron dicotomías como limpio/sucio y bello/ feo. El espacio cultivado se diferenciaba claramente de los otros espacios y su indiferenciación posterior lo hace aparecer como sucio, en el sentido de que contiene elementos que están fuera de su lugar. Ésta es una concepción asociada con una sociedad y una identidad campesinas y se corresponde con individuos socializados en esta sociedad del pasado y que adquirieron un habitus campesino. En el trasfondo hay una sociedad rígidamente estratificada — casas altas y casas bajas-, y jerarquizada — primogénito/no primogénito, viejos/jóvenes, etc.- - con un sistema de autoridad y control social que afectaba fuertemente los destinos de los individuos, como lo prueban entre otras cosas las elecciones matrimoniales. El control del patrimonio implica también el control de las categorías ecológicas y sociales en que se basa.

La segunda cosmología se estructura alrededor de la dicotomía natural/artificial. Una de sus referencias más destacadas es la oposición entre vivir en la naturaleza y vivir en la ciudad y por ello se la podría denominar urbana, por implicar un giro hacia lo natural, compendiado por lo rural. En relación al valle estudiado, la ausencia de intervención humana, de trabajo, consecuencia de la crisis agraria, provocó un deterioro del orden ecológico anterior basado en las dicotomías cultivado/silvestre y domesticado/salvaje. Quienes tienen un habitus campesino perciben que este cambio hace bascular irreversiblemente el territorio hacia el dominio de lo silvestre y lo salvaje, que consideran negativamente. Por el contrario, esto constituye la imagen misma de la naturaleza para los individuos con habitus urbanos como los neorurales y turistas de diversos tipos. El concepto paisaje se impone y esto indica la creciente importancia de la dimensión visual y contemplativa asociada con el territorio rural. La noción de naturaleza de los nuevos sectores sociales no tiene ni la misma forma ni la misma valoración que tiene lo silvestre y lo salvaje para los campesinos. Si los campesinos identifican el paisaje actual con la ausencia de intervención humana, los neorurales y turistas socializan la naturaleza al transferirle cualidades sociales, en el sentido de atributos de relaciones sociales, como paz, tranquilidad, serenidad, plenitud, libertad, bondad, etc. Es a causa de esta transferencia que la naturaleza es tan valiosa para ellos.

Si la cosmología campesina se correlaciona con una organización social posicional, con estatus sociales bien definidos, como la de la sociedad campesina, la concepción urbana de la naturaleza se correlaciona con una organización social más personal, porque los individuos, desvinculados de sus estatus anteriores, consideran que viven en la naturaleza y en un tiempo natural y porque la sociedad que les acoge, al colocarlos en una especie de limbo por medio de la categoría indiferenciada de recién llegados, no los integra conceptualmente. Están allí, pero no forman parte de ella ya que no comparten los mismos "supuestos fundamentales" (Bernstein citado por Douglas, 1978: 42).

La redefinición del territorio con el término naturaleza implica una naturalización del sector campesino de esta sociedad: antes vivían en la montaña, que definían como un país, ahora viven en la naturaleza, una naturaleza supuestamente original. Naturaleza se superpone a identidad campesina. Esta concepción naturalista del 
territorio es funcional para la economía terciaria que convierte la naturaleza en un recurso y en una mercancía. La dicotomía natural/artificial — químico es una de sus especificaciones - es un marco de referencia básico para los urbanitas en ciertos contextos de la medicina, la alimentación, la cosmética, etc., si bien la comparten también parcialmente quienes tienen un habitus campesino, por ejemplo, cuando se proclaman partidarios del agua de las fuentes en parajes naturales y muestran un cierto rechazo al agua clorada del depósito municipal, o cuando califican ciertos alimentos de naturales por oposición a artificial, pero también a ecológico. Ellos comen natural, pero no ecológico.

La tercera cosmología se basa en las oposiciones complementarias biodiversidad/ homogeneidad natural, autóctono/exótico e invasor/invadido. Domina en un mundo en que los flujos transnacionales de personas y especies causan un fuerte impacto sobre determinadas poblaciones locales y estados naciones y en el imaginario social (Appadurai, 1996).

A nivel local, la concepción de la naturaleza basada en la noción de biodiversidad está asociada con la creación de un parque natural, que conllevó la pérdida de una parte de los derechos de los habitantes sobre su territorio, y este contexto de poder y dominio marca la difusión y la recepción de esta concepción.

Biodiversidad es un concepto y un valor dominante que orienta y legitima políticas de protección y conservación de la naturaleza. La defensa de este principio implica la defensa de la naturaleza autóctona y el rechazo, la erradicación e incluso el exterminio de especies forasteras e invasoras. Los medios difunden a menudo noticias de este tipo: "Las especies exóticas invaden el ecosistema mediterráneo" (El País, 12-11-2006). "España alberga 1.400 especies invasoras" (20 Minutos Barcelona, 26-02-2009). "Peces sospechosos" (El País, 17-4-2010). "El ataque de los visones. Es una especie invasora que queremos erradicar, señalan fuentes de Medio Ambiente" (El País, 22-2-2010). "La invasión exótica de los ríos" (El País, 3-10-2011).

La gran difusión e importancia que ha cobrado la noción de biodiversidad y su distinción clave entre autóctono y foráneo ha generado poderosas imágenes naturales a menudo inscritas en demostraciones, experimentos, etc., de científicos y expertos que son presentadas como acciones científicas y técnicas de selección, depuración, protección, exterminio de elementos naturales, pero que transcienden el nivel científico-técnico para convertirse en metáforas del orden social y sus problemas. La presentación de dichas acciones aparentemente técnicas por los medios y las explicaciones y justificaciones que la propia presentación genera, les atribuye una dimensión ritual por cuanto celebran y difunden un valor natural, convertible en valor social por el contexto socio-político. El amor radical a la naturaleza autóctona se convierte fácilmente en amor radical a lo autóctono cultural y social.

Considero que la coexistencia de las tres cosmologías genera una tensión simbólica que refleja las relaciones de poder entre agentes y sectores sociales en el seno de un sistema social remodelado por la economía terciaria, a la vez que esta tensión simbólica constituye un marco y un recurso para la expresión de la discrepancia y el poder, ya que como afirma Wolf (1990: 593) "el poder es interno al significado". La 
tensión simbólica está relacionada con relaciones de oposición entre concepciones de la naturaleza y también a la inversión de la jerarquía de significados, valores y peligros por parte de una concepción dominante.

A cada una de las cosmologías le corresponde un lenguaje metafórico propio. La cosmología centrada en la oposición domesticado/salvaje, de raíz neolítica, genera símbolos "naturales", es decir, la naturaleza domesticada y la salvaje son convertidas en modelos y parámetros para roles y comportamientos humanos. Algunos ejemplos de símbolos "naturales" negativos son gorila para un dictador; serpiente para un enemigo a exterminar, sanguijuela para un usurero, lobos y osos para especuladores.

La cosmología basada en la oposición natural/artificial identifica y valora positiva y negativamente diversos tipos de elementos, que no son forzosamente especies, en función de si contribuyen o no a definir un estilo de vida natural, saludable, relajada, feliz — en la medida en que se hace depender la felicidad de la relación con la naturaleza-, etc ${ }^{2}$.

La cosmología basada en la noción de biodiversidad genera eco-símbolos, es decir, confiere a elementos de la naturaleza o de la sociedad una gran densidad de referencias y significados por medio de dos mecanismos complementarios: la patrimonialización y la mercantilización de lo auténtico. La patrimonialización es el resultado de una producción cultural en el presente que recorre al pasado" (Kirshenblatt-Gimblett, 2001: 44). La producción de patrimonio "cultural" y "natural" parte de una mirada selectiva informada por dos concepciones, una concepción de la historia y una concepción de la naturaleza, no como concepciones abstractas sino referidas a territorios específicos. La mercantilización de lo auténtico toma como referente "un valor de uso puro" (Boltanski y Chiapello, 2002: 559). Este mecanismo transforma elementos naturales o sociales, que no formaban parte de la circulación del mercado, y por tanto es como si hubieran estado fuera de la historia, en nuevas mercancías. Ambos mecanismos crean valores diferentes - valores patrimoniales y valores puros - que favorecen la acumulación de capital en una economía postfordista, que exige nuevos recursos y valores (Frigolé, 2010a ).

Un ejemplo de conversión de un símbolo "natural" en un "eco-símbolo" mediante la patrimonialización de una especie extinguida y recuperada por medio de la protección, y de la tensión simbólica que genera, nos lo ofrece el cambio de estatus del lobo: de enemigo a compañero. El lobo ha pasado de ser el símbolo "natural"

2 "El ministro de Finanzas de Suecia declaró: "Lo que estamos viendo es comportamientos en masa de manadas de lobos. Si no frenamos a esas manadas, destrozarán a los países más débiles." La Vanguardia, 10 de mayo de 2010, p.77. “¿Manadas de lobos al acecho del mercado?" Actualidad Económica, julio de 2010, p.66. "La palabra oso (que en inglés simboliza al pesimista, del mismo modo que el toro simboliza al optimista) sugiere una criatura irracional y furiosa, que arremete contra todo lo que encuentra a su paso. Por supuesto, igual que los osos animales, algunos osos bursátiles pueden ser muy salvajes. Los más excitables tienen un comportamiento más bipolar que unipolar. (...) El entusiasmo de los toros también peca a veces de irreal y los lleva a hablar de eras nuevas en las que la bolsa llegará a niveles máximos nunca soñados." "Por favor, den de comer a los osos", Actualidad Económica, octubre de 2010, p.28. Una imagen diferente del oso: "ciudadano plantígrado". El País. Especial Asturias. 01-12-2010, p.33. 
de la depredación más cruel a ser el símbolo de la biodiversidad y de la riqueza del patrimonio natural de un territorio, lo cual justifica su protección.

\section{Eco-símbolos y marcas en un mercado global}

La economía terciaria necesita bienes y servicios "auténticos" para satisfacer las demandas de estilos de vida y de consumo distintivos. Entre estos bienes hay que situar los territorios, que en anteriores sistemas productivos y económicos eran considerados básicamente como un factor de producción y que ahora se han convertido en un recurso y un bien en sí mismos. La autenticidad de los territorios no sólamente emerge como una cualidad fruto de la crisis de un sistema anterior, sino que es activamente construida por procesos de patrimonialización de sus paisajes y sus historias y culturas. El modelo de la autenticidad del territorio se construye sobre el modelo de lo autóctono y este, sobre una concepción de la naturaleza inspirada por la noción de biodiversidad. Lo natural autóctono deviene lo auténtico natural que hay que proteger. Así pues, lo autóctono proporciona los atributos de referencia para la construcción de lo auténtico, un diferenciador que genera valor añadido y que es uno de los motores de la economía terciaria. La caracterización de auténtico emerge mediante un conjunto de oposiciones contextuales, el polo positivo de las cuales está representado por términos como: local, autóctono, artesanal, respetuoso con la naturaleza, puro, sincero, etc. Una ilustración del ámbito de la gastronomía: el chef René Redzepi, del restaurante danés Noma, que ocupa desde 2010 el primer lugar de un ranking mundial de restaurantes, declara:

Nos gusta ser un reflejo de la sociedad actual, preocupada por el medio ambiente, contraria a las agresiones a la naturaleza y comprometida con la despensa nórdica. (...) Me limito a cocinar exclusivamente las materias primas del ámbito nórdico y evitamos cualquier producto previamente manipulado o industrial. Cocinamos lo más cercano en su temporada de plenitud, queremos reflejar lugar y clima mediante procedimientos artesanales (Cepeda, 2010).

El autor añade:

Retorno a los productos evidentes y a los sabores concretos y sinceros. Casi todo lo que se cocina en Noma sabe a lo que parece, aunque sea raro o insólito, como las bayas salvajes, los tréboles de acedera o las greñas del pino que recolectan los propios cocineros. La cocina de Noma se pliega con rigor al medio y al clima, a su ecosistema (ibid).

Redzepi se define a sí mismo y a sus veinticinco cocineros como "exploradores gastronómicos" (Rodríguez, 2011: 34) y añade: "para mí es más importante ver dónde y cómo crece una baya o a una abeja polinizando a una flor que va a formar parte de un plato único, que un kilo de caviar iraní” (Rodríguez, 2011: 35).

Las múltiples referencias a lo "nórdico" como lugar, naturaleza e identidad (despensa nórdica, materias primas del ámbito nórdico, proximidad al lugar, al clima, a la temporada, al ecosistema, reflejo de la sociedad) y al procedimiento "artesanal" (no industrial, no manipulado, no artificioso: una cocina que sabe a lo que parece, 
productos evidentes, sabores concretos y sinceros) son los elementos que caracterizan lo auténtico y justifican la frase introductoria del texto de Cepeda (2010): "retorno a lo auténtico".

Se puede dar todavía un paso más. Una representación de naturaleza autóctona se puede traducir en un modelo de lo auténtico a pequeña escala: "Los paisajes del País vasco y del campo japonés saltaron al plato en un juego de sutilezas y recuperación de las raíces locales". Los responsables son dos cocineros, uno vasco y el otro japonés. Éste elaboró un menú "basado en la naturaleza del bosque. Aromas, texturas y esencias trasladadas al plato. (...) Una sopa que sabe a paisaje" (Rivas, 2010: 42). Se designa este modelo culinario con el término "eco-cocina".

La autenticidad se ha convertido en una cualidad tan importante que es una condición sine qua non de otras cualidades o características distintivas, como la exclusividad que caracteriza el consumo de lujo. María Eugenia Girón, empresaria del sector del lujo y miembro de la ONG Oceana para la conservación del mar, afirma que "lo exclusivo del lujo es sinónimo de lo auténtico" (Sánchez-Silva, 2009). No hay exclusividad sin autenticidad y esta no existe sin referencia a una concepción de la naturaleza basada en la biodiversidad. El lujo se transforma en eco-lujo.

Los eco-símbolos, condensación de lo auténtico, son un valor básico para la economía terciaria. Su producción y transferencia a diversas esferas de la sociedad tales como la gastronomía, el turismo, la moda, la economía etc., exigen inversión. Empresas e instituciones invierten en eco-símbolos con el fin de fortalecer su marca y añadir valor a sus productos y servicios. La marca constituye un intangible vital para una empresa o institución y constituye su mejor protección. Algunos ejemplos de inversión en eco-símbolos: En México, el Grupo Modelo, líder en la fabricación de cerveza, asesorado por la ONG Pronatura y el gobierno, se ha convertido en un "icono de la conservación" mediante el liderazgo del Programa de Conservación del Parque Izta-Popo. En Francia, Michel Lacoste es el primer empresario que ha invertido en "la protección del animal que ilustra su logo, empezando por el cocodrilo del Ganges, amenazado de extinción" (Grousset, 2009: 66), en el marco de un programa gubernamental que estimula a las empresas a "invertir en la protección del vegetal o animal que simboliza su marca mediante la contrapartida de una importante deducción fiscal" (ibid: 68). En Italia, el empresario Zegna contribuyó por medio de un acuerdo con el gobierno peruano a la recuperación de la vicuña, que estaba amenazada de extinción. El acuerdo incluye "la construcción de un sistema de irrigación en plena cordillera de los Andes que garantiza una vida mejor a los criadores y suficiente alimento para las vicuñas" (ibid: 96) El gran incremento del número de vicuñas — más de 120.000 - garantiza su supervivencia y la continuidad del suministro de su lana. La transferencia a la marca del valor atribuido a la protección de la vicuña y a la lana como una materia autóctona y auténtica, la refuerzan. La protección animal y la comercialización de productos auténticos se han traducido en una ventaja monopolista: "Poder decir: 'Yo controlo de dónde sale la materia prima es mucho más importante hoy que hace seis meses', asegura Paolo Zegna" (Vázquez, 2009: 96). Una estrategia complementaria para asociar una marca al sostenimiento de la biodiversidad consiste en la concienciación de sus clientes. El árbol 
se ha convertido en un icono de la naturaleza y plantar árboles, cientos de miles de árboles, es el desafío que grandes empresas del sector consumo, tales como Wallmart o Yves Rocher, han lanzado a sus clientes para estimular su fidelidad. Otras empresas asocian su marca con el concepto de sostenibilidad, cuya traducción a un lenguaje contable y económico resulta familiar para la gente. Por ejemplo, una compañía aérea puede sugerir a sus pasajeros que hagan una contribución económica para compensar la emisión de $\mathrm{CO}_{2}$ que produce su vuelo. La idea de sostenibilidad es aceptada por muchas empresas por cuanto se relaciona con la innovación y modernización de los procesos productivos y, por tanto, con el ahorro, la proyección de una imagen positiva de una marca y un valor añadido que distingue y da excelencia competitiva al producto.

Douglas (1978: 14) utiliza el término sistema natural de simbolización y lo define como "un sistema común a todas las culturas, recurrente y siempre inteligible" determinado por sistemas sociales afines. Considero, en efecto, que los símbolos "naturales" y eco-símbolos son dos tipos de símbolos propios de culturas que se correlacionan con sistemas sociales diversos. Los símbolos "naturales" forman parte de un sistema de clasificación que separa naturaleza de sociedad y en el que la naturaleza domesticada y salvaje es concebida como un recurso real y simbólico para la sociedad. Los símbolos "naturales" reflejan relaciones de poder y son instrumentos de poder por su capacidad para deslegitimar e incluso deshumanizar identidades y estatus. En este contexto la figura del lobo, reaparecido tras su extinción, es en la sociedad campesina un símbolo natural "condensado" (ibid: 30 ), porque concentra numerosas referencias ya expuestas y que ahora resumo: reforzamiento de la distinción domesticado/salvaje; "naturalización" del territorio; atentado contra los intereses ganaderos; retroceso hacia el pasado y asimetría entre territorios; indefensión frente a un animal intocable; menosprecio hacia los antepasados; afrenta a la dignidad de los habitantes locales; etc. El sistema social que genera eco-símbolos aspira, por el contrario, a superar la separación entre naturaleza y sociedad mediante actitudes éticas y un lenguaje social que en el ejemplo del lobo da lugar a términos tales como: compañero, integración, convivencia, etc. En este sistema social, el lobo no puede devenir un símbolo de deslegitimación o de deshumanización de identidades y estatus.

\section{Transformaciones en un valle Pirenaico: naturaleza salvaje y parque na- tural en un contexto global}

Un directivo de una organización ecologista mexicana propone "resilvestrar" América latina, porque las "tierras silvestres" son "la esencia de la naturaleza prístina" (S/a, Escala, 2010: 82-83). La organización Rewilding Europe, creada en 2010: "pretende hacer de Europa un territorio más salvaje, con mucho más espacio para la vida y la naturaleza salvaje y los procesos naturales, mediante el asilvestramiento de un millón de hectáreas de tierra en 2020 y la creación de 10 magníficas áreas de vida y naturaleza salvaje de calidad internacional"’3.

\footnotetext{
${ }^{3}$ (http://www.rewildingeurope.com/news/articles/ .Consultado: 20/09/2011)
} 
Su objetivo es la creación de safaris europeos parecidos a los africanos.

La noción de naturaleza salvaje (wilderness) nos sitúa en el corazón de transformaciones ecológicas, sociales y económicas contemporáneas que afectan a diversos territorios y de las disputas por su significado y por el control territorial. Los significados de "wilderness" están mediatizados directamente por los principios y las categorías de las diversas cosmologías que se encuentran confrontadas y no por propiedades objetivas.

Presento a continuación el caso etnográfico enmarcado en dos contextos, uno histórico, el parque natural como modelo de protección, y otro territorial, el proceso de asilvestramiento de otros territorios de montaña europeos.

En primer lugar, especifico brevemente el enfoque que adopto en la exposición del caso etnográfico. Sigo la recomendación del historiador Marc Bloch: "Mirar primero al presente para interpretar mejor el pasado" (citado por Descola, 2005: 14).

Tres factores han sido básicos para que la economía terciaria se haya convertido en dominante en este valle pirenaico y en su entorno a inicios del siglo XXI: la crisis de la economía campesina, que creó las condiciones para la remodelación del medio natural, visible en el avance del bosque sobre las antiguas tierras de cultivo, proceso percibido como natural, pero que esconde el cese de la actividad productiva campesina; una nueva conceptualización del medio físico y social y finalmente, unas nuevas prácticas de los agentes sociales de acuerdo con dos estrategias básicas, la patrimonialización y la mercantilización de lo auténtico, dos estrategias que se complementan y refuerzan mutuamente en el marco de la economía terciaria (Frigolé, $\left.2010^{\mathrm{a}}\right)$.

El territorio era un factor de producción en la economía campesina, mientras que para la economía terciaria deviene un bien en sí mismo. El sistema productivo campesino implica una delimitación clara del espacio y de sus usos de acuerdo con la distinción domesticado/salvaje. La crisis de este sistema generó una realidad y una imagen de un territorio más indiferenciado, un territorio "naturalizado" que debía ser protegido.

El 1983 se crea el Parque Natural del Cadí-Moixerò con el objetivo de proteger un territorio definido por sus "valores naturales", que conforman un patrimonio natural. En síntesis, estos valores son: "una variedad de paisajes, ecosistemas forestales, zonas rocosas, diversidad geológica y de fósiles, prados y una extensa flora y fauna con especies de ámbito mediterráneo al lado de alpinas y eurosiberianas. (...) más de 1.500 categorías de plantas y más de 240 especies de vertebrados (El Picot Negre 2003: 5).

Los directivos del parque afirman que "los territorios de montaña que ocupa el parque atesoran una de las mayores cotas de biodiversidad de Cataluña" (García Petit y Alcántara Guirado, 2008:7). Por ello lo consideran una "marca de calidad" que aporta "valor añadido" al entorno del parque y a las actividades que se desarrollan en él (García Petit y Alcántara Guirado, 2008: 5-6).

Esbozo a continuación una breve genealogía histórica de la figura del parque natural. Este modelo de protección nació en el siglo XIX y fue una de las consecuencias de la colonización de asentamiento (settlement). Según Wolfe (1999: 2), 
"las colonias de asentamiento se basaban en la premisa de la eliminación de las sociedades nativas". No solamente las exterminan, sino que también transforman radicalmente sus medios naturales: "los grandes estados resultado del asentamiento como Argentina, Australia, Brasil, Canadá, Rusia y los Estados Unidos promovieron experimentos ecológicos continentales, que transformaron las praderas en campos de cultivo y los bosques en plantaciones" (Berglund \& Anderson, 2004:1). En América del Norte, a finales del siglo XIX, "más de cincuenta millones de bisontes, la base de la economía de los indios de las llanuras, fueron sacrificados durante las guerras indias" (Johansen y Maestas, 1982: 30) con la finalidad de vencer y erradicar definitivamente a los indios. Según Berglund y Anderson (2004: 5), el mito de la frontera que "hizo posible que los colonizadores blancos justificasen la desposesión y la matanza de las poblaciones indígenas de los Estados Unidos" fue también "el mito fundador del proteccionismo ambiental americano". Se trata de una visión "de una naturaleza salvaje no habitada" (Cronon, 1995:79). Estados Unidos ${ }^{4}$ crea el primer parque nacional en 1872 y siguen su ejemplo "Australia (1886), Canadá (1887), Nueva Zelanda y África del Sur (1898)" (Lefeuvre, 1990: 32). La naturaleza virgen fue aquella de la que se había suprimido la población. El nexo entre erradicación y exterminio de poblaciones aborígenes y protección de un territorio deshumanizado queda escondido por la metáfora "santuario de la naturaleza", en cuanto enfatiza que un parque es escenario de "una grandiosa puesta en escena de la obra divina" (Descola, 2005: 89).

La noción de naturaleza salvaje legitima procesos de control por parte del estado sobre un territorio. El estado australiano contemporáneo la aplica a territorios de los aborígenes con las "connotaciones de terra nullius, de naturaleza original y preservada, de ecosistema a proteger en contra de las degradaciones de origen antrópico" (ibid: 62), para justificar las medidas de protección ambiental. Salvaje se relaciona con biodiversidad, un valor positivo, que la protección del estado convertirá en patrimonio natural nacional.

En el caso del valle pirenaico catalán, la política de protección ambiental implica cambios en el derecho de propiedad y en la jurisdicción sobre el territorio. El Parque Natural (1983) amplió y reforzó una política de protección iniciada con la creación de la Reserva Nacional de Caza del Cadí (1966), cuya finalidad cinegética estaba subordinada al fomento y conservación de ciertas especies amenazadas. Anteriormente, la población local había cazado sin ninguna o con pocas restricciones animales que tenían fundamentalmente un valor de uso, excepto ciertos elementos de algunos animales, como la piel, que tenían un valor de cambio. La efectividad de la protección la ponen de manifiesto las siguientes cifras: en 1968 se contabilizan 75 rebecos (capra ibex) y en 2004, 2.363. La Reserva de Caza y el Parque Natural se complementan en la gestión y el control de este patrimonio vivo. Uno de los medios utilizados para este fin es la caza. Se crearon nuevas modalidades

${ }^{4}$ En Brasil, en la década de 1960, la junta militar, en nombre de la seguridad nacional frente a una infiltración comunista, "declaró la Amazonía, una frontera donde se podía disparar legalmente. Subsiguientemente se convirtió en el lugar del genocidio indio y de la especulación salvaje de la tierra." (Watts, 1992: 116) 
de caza y procedimientos nuevos para acceder a ella. Una es la caza de trofeo, que designa una modalidad de caza competitiva. Otra es la caza selectiva, que tiene como finalidad eliminar los animales naturalmente defectuosos, así como también los defectuosos según los parámetros de excelencia que exige la caza de trofeo. Las dos categorías de caza se relacionan con un valor máximo y un valor mínimo. El mecanismo de acceso a la caza selectiva es la concesión de permiso de la administración a determinadas categorías de cazadores prefijadas, entre otras a la población local, mientras que el mecanismo de acceso a la caza de trofeo es la subasta, es decir, la mercantilización hasta el máximo posible del derecho de caza de un animal considerado emblemático de un lugar. Todo esto implica un cambio substancial en el valor de algunos animales y de la caza. Un guarda mayor de la Reserva Nacional de Caza del Cadí caracteriza los cazadores que acompañó a lo largo de casi treinta años en la caza de trofeo del rebeco: "Gente de México, de Brasil, de Alemania, de Italia, de Francia, de Estados Unidos, por no hablarte de la gente del Estado español. Empresarios, banqueros, personas con títulos nobiliarios... mucho dinero, la verdad. La caza que practican esta gente es un lujo" (Pardinilla, 2006: 23). La caza deportiva internacional de trofeo es "una iniciativa 'de conservación - comodesarrollo' convertida en un elemento clave en la planificación de la conservación a nivel mundial" (Macdonald, 2004: 72).

La política de protección ha contribuido a la recuperación de otras especies, una de les cuales es el lobo, desaparecido desde hace generaciones. Desde el Parque Natural se considera que "la reaparición del lobo es un proceso natural que hay que incluir en la mejora del medio ambiente" (García Petit, 2004: 11), pero en diversos municipios del Parque, la expresión usual de la gente para referirse al lobo es "lo han llevado". Jordi Pardinilla, periodista local, me dijo: "La gente no cree que no hayan llevado el lobo, porque mostraron por televisión la reintroducción del oso" (2009). Para la gente local, la reaparición del lobo no se percibe como un proceso natural.

Mientras el director del Parque apela a "la memoria histórica" genérica (García Petit, 2004: 11) para legitimar la reaparición del lobo, dos ganaderos, residentes en dos extremos del Parque, adoptan un punto de vista exclusivamente familiar para cuestionarla: "Son los únicos animales (lobo y oso) que los antepasados exterminaron y esto por alguna cosa será" (ganadera, 2009); "si nuestros antepasados los echaron, por alguna razón debía ser" (ganadero, 2008).

El director del Parque establecía una clasificación de la gente según su actitud en relación a la reaparición del lobo:

muchos, sorprendidos por haber recuperado un animal emblemático de la fauna europea; otros, preocupados por las repercusiones que esta aparición pueda tener sobre los rebaños domésticos; unos cuantos, pensando en él como un nuevo atractivo turístico de estos valles; la mayoría, entre indiferentes y curiosos delante de la presencia de un animal que despierta pasiones allá donde regresa (García Petit, 2004: 2). 
La clasificación ignora las actitudes abiertamente contrarias a la presencia del lobo y a la política de la administración (Frigolé, 2010: 168-171).

El 12 de febrero de 2004, el Consejero de Medio Ambiente del Gobierno de Cataluña informó en rueda de prensa de la identificación de un lobo dentro del Parque Natural del Cadí-Moixeró a partir del análisis genético de un excremento. La noticia se acompañó con la siguiente previsión:

A partir de ahora se prevé hacer un seguimiento detallado de esta especie para hacer compatible su presencia con las diferentes actividades humanas que se realizan en la naturaleza. La recuperación de antiguas tradiciones de gestión de los rebaños, como los cercados nocturnos en la montaña y los perros protectores, ha de ayudar a hacer posible la convivencia pacífica entre hombre y lobo (El Picot Negre 2004: 3).

Ricard, un pastor de 32 años con un rebaño de ovejas de tradición familiar, me comentó la expresión "convivencia pacífica entre hombre y lobo" diciendo que consideraba "injusto e incongruente que a ellos se les quiera hacer retroceder ciento cincuenta años con la reintroducción de animales como el lobo y el oso y que el resto del territorio no esté dispuesto a retroceder ciento cincuenta años en cuanto a las formas de vida, prescindiendo de autopistas, coches, etc.," (2009).

Lo plantea en términos de desigualdades territoriales: a su territorio le imponen un salto atrás, mientras que a los territorios más urbanizados, no. Joan Pubill ganadero y exalcalde de uno de los municipios del Parque afirmaba de manera semejante que:

no le parece correcta la situación "postiza" que se ha querido provocar con la reintroducción de estas razas (el lobo y el oso) en el Pirineo. (...) Desde la Administración, desde los despachos de Barcelona, se observa el área pirenaica como un tipo de jardín y reserva de fauna, para el goce de los habitantes de la área metropolitana cuando vienen los fines de semana (Pardinilla, 2008: 27).

Joan Pubill considera el lobo como un gran enemigo para el ganadero de los Pirineos, "porque mata una oveja, pero abortan diez y la administración solo indemniza por el animal muerto" (2005). Ricard puntualiza: "No se trata de una oveja, sino de mi oveja". E introduce la siguiente referencia para defender su posición:

Si yo atropellara a un animal de compañía y dijera "ya lo pagaré", la gente no lo consideraría suficiente. Los ecologistas también protestarían. Así pues, tampoco es suficiente la indemnización por la oveja, ya que no es sólo una oveja sino mi oveja, un animal que conozco, que me da satisfacciones (2009).

Ricard acaba diciendo que hace collares de madera, que la gente se los quiere comprar, pero él se los pone a sus ovejas. El se opone a la racionalidad meramente económica que contempla el animal como un mero valor de cambio, el que se ha impuesto en la caza de trofeo.

Presento a continuación unas referencias al proceso de asilvestramiento de otros territorios europeos. Para las poblaciones campesinas y ganaderas de áreas de 
montaña de Europa el significado de "wilderness" remite a su cosmología centrada en la oposición domesticado/salvaje. Stacul (2003: 147) sostiene que las expresiones "Hoy todo es salvaje aquí" o "(El territorio) solía estar limpio, abierto, hoy es como una prisión" son frecuentes entre la gente mayor de un valle de los Alpes italianos. Stacul las contextualiza mediante la referencia a los siguientes hechos:

La línea divisoria entre el pueblo y el bosque, entre lo domesticado y lo salvaje se ha borrado (...) El despoblamiento y el abandono del sistema agrícola-pastoral han tenido un papel decisivo en la aceleración de este proceso, aunque los actores sociales lo relacionan con el hecho de que se necesita un permiso especial para disparar contra los animales y cortar árboles (ibid: 147).

Los ganaderos de los Alpes franceses denuncian el proceso de "de - $\mathrm{O}$ anti- domesticación" (Mauz, 2006: 9) que experimenta su territorio como una consecuencia de la introducción y reintroducción de diversas especies de animales salvajes. Para los ganaderos:

los Alpes se vuelven salvajes a un ritmo acelerado y la presencia de especies (re) introducidas es la prueba patente de la existencia de una voluntad compartida por muchos. Ellos (los ganaderos) no consideran las (re)introducciones como disociadas las unas de las otras, sino como elementos de un proyecto global y coherente (ibid: 8 ).

Chandivert (2010: 128), refiriéndose al Pirineo central francés, afirma que hay dos discursos sobre el patrimonio, uno por parte de los partidarios de la reintroducción del oso y el otro por parte de sus oponentes. Estos denuncian la reintroducción del oso "como un intento de volver salvaje el macizo y argumentan por el contrario a favor de una "biodiversidad normal" basada en ovejas y vacas" 5 .

En el Pirineo catalán, la población con un habitus campesino considera que la reaparición del lobo después de su extinción total sólo se explica por la acción planificada de las autoridades del Parque Natural. Algunos incluso opinan que después de haberlo reproducido en una granja — el modelo de cría y producción ganadera principal - lo han soltado. Esta visión sobre la artificialidad del proceso tiene una implicación para la concepción de la naturaleza salvaje del lobo actual. Según Mauz (2006: 5), los cazadores y los ganaderos de los Alpes franceses "tienden a oponer los animales salvajes a los domésticos y a esperar de los primeros que se muestren tan miedosos y ariscos como se considera que los segundos son mansos y dóciles". Es en relación a esta oposición que:

el animal (re)introducido es percibido como posiblemente, si no probablemente, con un comportamiento anormal. La mayoría de ganaderos de ovejas se muestran convencidos de que los lobos han sido reintroducidos en los Alpes, como mínimo ciertos lobos: los que, al no tener miedo de acercarse a los rebaños y a los núcleos habitados, causan problemas (Mauz, 2006: 8)

\footnotetext{
${ }^{5}$ Ver también Vaccaro y Beltrán (2010).
} 
Los animales eran más salvajes antes, porque los perseguían más y por ello vivían en espacios separados. El animal salvaje huye del hombre. Si se le acerca, es porque se desvía de su naturaleza salvaje ${ }^{6}$. Por ello los lobos que se acercan a los rebaños y lugares habitados son considerados reintroducidos y, por tanto, no salvajes del todo, seres desviados, modificados en su comportamiento animal por el hombre.

Douglas (1991: 56-57) ha escrito sobre las connotaciones teológicas de la oposición domesticado /salvaje:

Hasta cierto punto los hombres pactaban con su país y ganado del mismo modo que Dios pactaba con ellos. Los hombres respetaban a los primogénitos de su ganado y los obligaban a respetar el sábado. Literalmente se domesticaba al ganado como si se tratara de esclavos. Tenían que ingresar dentro del orden social para poder disfrutar de la bendición. La diferencia entre el ganado y las fieras consistía en que las fieras no tenían pacto que las protegiese.

El nuevo pacto con la naturaleza, que incluye a los animales salvajes, inspirado por la cosmología centrada en la noción de biodiversidad, se basa en nociones éticas como responsabilidad y respeto.

En el valle estudiado, el desarrollo de la economía terciaria ha implicado la remodelación material del espacio y de sus elementos como casas, iglesias, caminos, etc., así como la transformación de la estructura social anterior por la incorporación de nuevos estatus y la modificación de sus relaciones y la reconfiguración de actividades productivas. Un ejemplo: los escasos ganaderos de vacas que restan se integran dentro de la economía terciaria en la medida en que crían y venden ejemplares de una vaca autóctona o de vacas criadas en pastos, fuera de las zonas habitadas, un procedimiento considerado natural y compatible con el interés y la estética dominantes, asociados con la economía terciaria. La recuperación de un elemento del pasado y la vinculación al territorio son la base de las cualidades autóctono y auténtico que añaden valor a las mercancías en la economía terciaria.

Las prácticas de la economía campesina son minoritarias y residuales, pero persiste una concepción y un habitus campesino de la relación del hombre con el medio natural, no como una inercia ni como una supervivencia, sino porque se han convertido en un factor de resistencia a la erosión que ha sufrido la posición social de los campesinos y a su pérdida de control sobre el medio natural.

La economía terciaria ha producido una redefinición de la identidad del espacio rural, sobretodo el de montaña, y de sus habitantes. Este espacio ha sido redefinido como naturaleza y paisaje, y esto ha cambiado la identidad de la población, que ha pasado de vivir en el campo y vivir de la tierra a vivir en la naturaleza y a vivir de ella. Los habitantes de esta área de montaña vivían en el campo, trabajaban la tierra y eran campesinos, pero no vivían en un espacio conceptualizado como natural ni como naturaleza. La montaña era un lugar de fatiga, no de ocio. Era un espacio y

${ }^{6}$ Los jabalís, "le han perdido el miedo al hombre. Y hasta el respeto. En el Parque Regional de la Maremma, incluso se dejan fotografiar, y si te descuidas, te roban el helado." Julio José Ordovas. "Donde la Toscana se asilvestra". Altaïr, nov-dic. 2009, 66. 
un mundo donde dominaba lo cultivado y lo doméstico y donde se esforzaban por alejar lo silvestre y lo salvaje.

La identidad campesina, dominante anteriormente, ha sido eclipsada e incluso marginada por el proceso de naturalización del espacio y de su población. La nueva concepción de la naturaleza se ha construido mediante la transferencia al paisaje de propiedades sociales como paz, tranquilidad, etc., y también mediante un nuevo canon estético que impone el uso de materiales tales como la piedra y la madera considerados congruentes con las nuevas formas y cualidades que la economía terciaria propugna para el medio físico y social. La política de las administraciones es evitar el impacto visual de las construcciones y elementos que se incorporan al habitat. Por ejemplo, se construye un depósito de agua para la extinción de incendios y se le reviste "de piedra de la zona para conseguir una buena integración paisajística" o se colocan barreras de madera en vez de metálicas, porque ofrecen "una gran integración paisajística". En relación a los materiales usados en la reconstrucción de casas y de iglesias, ver Frigolé (2010: 164-167).

Desde la década de 1970 hasta el presente, el valle ha recibido sucesivas migraciones de neorurales, los primeros de los cuales fueron conocidos como 'hippies'. Para estos la elección de un modelo de vida libre determinó la elección del lugar de residencia y la manera de ganarse la vida, mientras que para los neorurales posteriores, la elección de un lugar de residencia identificado ya con una forma de vivir determinó la forma de ganarse la vida. La progresiva acción reguladora del estado sobre las actividades productivas y comerciales y la progresiva integración del territorio en la economía terciaria disciplinaron gradualmente vidas y actividades conceptuadas como libres.

Una de las primeras neorrurales en instalarse en el valle, que realiza tareas domésticas en el sector turístico, afirmaba (2005): "Me llena vivir en la montaña. No cambiaría estos treinta años vividos aquí por cuarenta y cinco vividos en Barcelona". Ella no llegó al valle desde la ciudad, sino desde un pueblo de otra zona de los Pirineos. Una pareja neorural más reciente, que trabaja en el sector servicios, al preguntarles sobre sus motivos para venir a vivir en el valle me respondieron: "Te tiene que gustar vivir en la montaña, no las flores. Te tiene que gustar lo salvaje" (2005). En su respuesta hay también una manera implícita de afirmar la dureza de la vida en la montaña y de aludir a su fortaleza. El término montaña es a menudo usado por los neorurales, por ejemplo cuando relatan su experiencia en términos de "mi vida en la montaña" o se interrogan entre sí, como cuando en el marco de un curso de capacitación laboral, la monitora, una neorural, preguntaba a cada una de las alumnas, casi todas neorurales: “¿Qué buscabas al venir a la montaña?”. Un neorural que había trabajado de mecánico en la ciudad, me dijo (2006): "Ni que hubiera habido que hacer de mecánico, sería un lujo hacerlo en este entorno". Un profesional, un neorural más reciente que los anteriores, afirmaba (2006): "Vivir en el valle es un lujo". Privilegio es también otro término de referencia.

Los neorurales usan el término montaña en singular al igual que lo hacen los habitantes que se consideran "del país" y que a veces se auto-identifican como "los de 
la montaña”. Los neorurales se diferencian así de los turistas que tienden a referirse a montañas, paisaje y naturaleza.

Vivir en la montaña se define por oposición a la ciudad, en cuanto se destaca que es un medio no rodeado de asfalto y cemento, sin contaminación, ruido, estrés, sin colas, etc., El desarrollo de la economía terciaria fomenta no solo una visión antiurbana, sino también anti-campesina, en el sentido de la negación, rechazo e incluso prohibición de actividades y elementos campesinos que se consideran ni asimilables ni compatibles con los intereses y la estética dominantes y que por tanto se declaran anti-estéticos o molestos (Frigolé, 2010: 175). Se construye una noción selectiva de naturaleza tal como pone de relieve el siguiente texto:

La naturaleza siempre está ahí, dispuesta a acogernos y hacernos sentir mejor. En ella no sólo nuestros pulmones y sangre agradecen el aire más limpio. También podemos apreciar la belleza de unas formas que rompen con el mundo rectilíneo creado por el ser humano; dejar que el pensamiento se ordene, apaciguado por la tranquilidad del entorno, o disfrutar de los elementos en estado puro y recuperar el gusto por lo simple. Además, la inmensidad de los paisajes y el orden natural con que transcurre la vida de plantas, animales y rocas permiten sentirse parte de algo más grande que uno mismo y aprender a tomar distancia de lo que nos preocupa. Y es el contacto con la tierra, el agua y el aire limpios, abrazar un árbol, tocar el musgo, o dejarse inundar por el olor a umbría del camino, ofreciéndonos la posibilidad de vivir la naturaleza como una parte nuestra, digna de amor, respeto y cuidado. Por ello es más que recomendable planificar salidas al mar o a la montaña. Se regresa más sereno, lleno de energía y consciente de la conexión con uno mismo y con el universo (Salgado, 2010: 36-37).

Después de la crisis de la economía campesina y la despoblación subsiguiente del valle pirenaico estudiado, el territorio es reconfigurado con unos valores naturalistas que generan sensaciones naturalistas únicas, deseadas por los visitantes urbanos. No se trata de romanticismo, sino de un movimiento que convierte el valor puro de "la naturaleza espectacular", potenciado por la protección, en un valor de cambio en el marco de una economía terciaria.

La visión de una naturaleza recuperada, retornada a su estado prístino, es decir, una visión atemporal del medio natural, tiene repercusiones sociales. Por ejemplo, difumina o borra las formas y la idea de campo al convertirlo todo en naturaleza, cosa que favorece lo que los locales llaman la "invasión" de los turistas; la transferencia al medio natural de las cualidades sociales como paz, tranquilidad, etc., atribuye un valor añadido a parajes y habitats, lo cual genera nuevas mercancías y nuevas formas de mercantilización.

La crisis del campesinado y la política de protección ofrecen al turista una naturaleza desconocida; la patrimonialización le ofrece una historia y una cultura recuperadas y la mercantilización de lo auténtico, unos productos antes desconocidos como tales y ahora con un valor añadido.

La lógica y la dinámica del sistema económico y social terciarios hacen que ciertos agentes sociales y comportamientos aparezcan como centrales y otros como marginales, y que unos sean alabados y otros, criticados. La crítica a una mujer por su 
resistencia a vender una casa en ruinas en un contexto de fuerte demanda estimulada por normas urbanísticas restrictivas, venta que habría representado la oportunidad de una importante ganancia, habría sido alabanza en el sistema social y económico anterior, ya que esta actitud es congruente con la noción de patrimonio familiar. Dicho de otra manera, la crítica actual por la negativa a vender habría podido hallar un equivalente simétrico pero inverso en el sistema anterior ante la venta de un bien patrimonial. La crítica a un comportamiento considerado irracional desde el punto de vista de la racionalidad económica dominante fue acompañada del recuerdo selectivo de la biografía de la mujer para atribuir a una personalidad desviada, la explicación de su negativa a entrar en el mercado inmobiliario. La importancia que en la actual economía terciaria se atribuye a los artesanos rurales no tiene que esconder la etapa en que estos, llamados 'hippies', eran considerados marginales. Ni el calificativo prestigioso de "pueblo de artesanos", casi una marca comercial, no tiene que esconder el calificativo anterior menos prestigioso de "pueblo de hippies". La visión negativa inicial de los hippies por parte de los habitantes locales tenía que ver con su apariencia, pero sobretodo con la percepción de la pérdida de valor que la presencia de los hippies comportaba para un territorio que experimentaba un proceso acelerado de "naturalización" como resultado del colapso de la economía y del sistema social campesino. Aceptar que el territorio se convirtiera en un refugio de fugitivos de la ciudad y de la civilidad implicaba aceptar que se convirtiera también en algo más salvaje y más marginal.

Esta perspectiva temporal implica una cierta deconstrucción y es básicamente relacional a partir de los contextos presentes, que son los que definen oportunidades y retos y plantean dilemas, tensiones y conflictos internos y externos a los diversos agentes sociales. La perspectiva temporal elegida es congruente también con el protagonismo que la patrimonialización y la mercantilización de lo auténtico tienen en la economía terciaria. Las dos estrategias manipulan elementos del pasado a partir de una determinada concepción de la historia, creando nuevos valores culturales y económicos, dos dimensiones estrechamente relacionadas en una economía terciaria. Un breve ejemplo: parte de las mujeres del valle pirenaico salían a vender durante algunas estaciones del año hierbas y remedios por toda Cataluña (Frigolé 2005). A finales del siglo pasado, unas décadas después de desaparecer esta actividad comercial, las mujeres vendedoras de hierbas fueron transformadas en figuras de un museo local. En el pasado no gozaban de prestigio social, pero la patrimonialización las transformó en símbolos destacados de la identidad del territorio, con una gran repercusión sobre el turismo. El proceso de "naturalización" del medio ha borrado el modelado anterior y lo homogeneiza, lo cual crea un escenario congruente con la recuperación de las mujeres vendedoras de hierbas como figuras de museo. La celebración de las mujeres vendedoras de hierbas es también una celebración de la naturaleza recuperada. La cultura incorpora y elabora elementos del pasado congruentes con las transformaciones sociales, económicas y del medio. La cultura tiene un papel destacado en la economía terciaria por el hecho de que la transferencia de tradiciones simbólicas, orígenes y concepciones diversas, entre otras las 
referidas al medio, genera valor añadido. Y las vías principales de esta transferencia son la patrimonialización y la mercantilización de lo auténtico.

\section{Consideraciones finales}

Para cerrar el texto, unas breves consideraciones sobre la producción de patrimonio y la relación entre globalización y práctica etnográfica.

La producción de patrimonio "cultural" y "natural" parte de una mirada selectiva informada por dos concepciones, una concepción de la historia y una concepción de la naturaleza, no como concepciones abstractas sino referidas a territorios específicos. Las dos concepciones contribuyen a definir la noción de autóctono. El patrimonio es el resultado de una mirada selectiva desde el presente hacia el pasado de un territorio y de sus elementos naturales y culturales. Esta mirada selectiva implica una percepción, valoración y conceptualización sobre el pasado, un pasado que no ha desaparecido del todo puesto que ha dejado su impronta en el territorio. Los objetos de la mirada selectiva y valorativa son heterogéneos y pueden gozar de valoraciones diversas en el momento de su conversión en valores patrimoniales, desde objetos o elementos devaluados hasta otros que gozaban de una gran valoración. Producción de patrimonio significa generar patrimonio nuevo, es decir, convertir en patrimonio aquello que no era valioso, pero significa también mirar y valorar de una manera diferente aquello que ya era considerado valioso. El patrimonio es el resultado de una mirada y de una toma de disposiciones específicas y diferentes sobre objetos y elementos naturales y culturales. Uno de los aspectos más interesantes del proceso de patrimonialización es la creación de eco-símbolos y por medio de ellos la transferencia de la cualidad de autenticidad a los diversos ámbitos de la sociedad y el impulso a la comercialización de lo auténtico. Esta transferencia tiene muchas implicaciones, desde proporcionar una posición ventajosa en el mercado, a la creación de nuevas mercancías, nuevos estilos de vida y de consumo y nuevos imaginarios.

Sobre la relación entre globalización y práctica etnográfica, presento en primer lugar algunas de las referencias que han orientado mi investigación y mi análisis etnográfico. Wolf (1982) mostró que los objetos de estudio tradicionales de la antropología son construcciones históricas, resultado de procesos de incorporación o imbricación específica de universos locales en el sistema capitalista mundial. Edelman y Haugerud (2005) proponen evitar la deshistorización de la globalización y Ferguson (2002) rechaza los conceptos lineales y unilineales, la elaboración de una secuencia de desarrollo de las formas sociales y culturales y explora su coexistencia temporal. Una formulación bastante precisa de la articulación entre lo global y lo local está condensada en la siguiente cita de los geógrafos Hadjimichalis y Papamichos (1990: 192): "los procesos globales se modifican y reproducen mediante su inserción en estructuras productivas particulares, procesos únicos de trabajo, clase, género, jerarquía étnica, y dominación institucional y cultural, que caracterizan a regiones y localidades específicas".

La transformación de un valle pirenaico, su impacto y su lógica han sido una prioridad de la investigación. El proceso histórico reciente se caracteriza por la 
emergencia y dominio de una economía terciaría que comporta el desplazamiento y la marginación de ciertas formas económicas, sociales y culturales (Frigolé 2006). El principio de coexistencia temporal, al que me he atenido, ha impedido que la marginación social de ciertas formas se trasladara al ámbito de la representación etnográfica, presentándolas como reliquias o supervivencias. Diversos autores señalan que es preciso hacer "tocar tierra" a la globalización mediante la investigación empírica en espacios y tiempos específicos. El estudio de la estructura social y de las clasificaciones simbólicas proporciona este anclaje. El contraste entre las clasificaciones introduce la idea de diferencia cultural. No se trata del concepto de cultura como sustancia que distingue un territorio de otro, sino de diferencias culturales en el seno de un mismo espacio y tiempo. La determinación social de las diferencias simbólicas remite a un único sistema social, heterogéneo por las diferencias de clase, ocupación, generación, origen y género que contiene. En el contexto de la articulación entre lo local y lo global, incluido el estado, he prestado atención al Parque Natural, un proyecto institucional, que me llevó a expandir la investigación más allá de los límites del valle. En este sentido, he introducido cambios de perspectiva y distintos tipos de datos, etnográficos o no, como muestra el tratamiento del asilvestramiento del paisaje y eco-símbolos, al destacar su creciente protagonismo en el medio, en los imaginarios y para las marcas en el contexto de la economía neoliberal.

\section{Referencias bibliográficas}

APPADURAI, Arjun

1996 Modernity at large. Minneapolis: University of Minnesota Press.

BOLTANSKI, Luc; CHIAPELLO, Ève

2002 El nuevo espiritu del capitalismo. Madrid: Akal.

BERGLUND, Eeva and ANDERSON, David

2004 "Introduction. Towards an Ethnography of Ecological Underprivilege", en D. Anderson and E. Berglund (eds.), Ethnographies of Conservation. Environmentalism and the Distribution of Privilege. New York: Berghahn Books, $1-15$.

CARRIER, James (Ed.)

2004 Confronting Environments. Local Understanding in a Globalizing World. Walnut Creek: AltaMira Press.

CHANDIVERT, Arnauld

2010 "Pastoralism and Heritage in the Central Pyrenees: Symbolic Values and Social Conflicts", en I.Vaccaro y O.Beltran (eds.), Social And Ecological History Of The Pyrenees: State, Market, And Landscape. Walnut Creek, CA: Left Coast Press, $127-141$.

CEPEDA, Lluís

2010 "Noma Copenhague". Paisajes, septiembre. 
CRONON, W.

1995 "The trouble with wilderness; or, getting back to the wrong nature", en W. Cronon (ed), Uncommon ground: Toward reinventing nature. New York: W.W: Norton, 69-90.

DESCOLA, Philippe

2005 Par-delà nature et culture. Paris: Gallimard.

DOUGLAS, Mary

1978 Símbolos naturales. Exploraciones en cosmología. Madrid: Alianza Editorial.

1991 [1966] Pureza y peligro. Un análisis de los conceptos de contaminación y tabú. Madrid: Siglo XXI.

DURKHEIM, Émile; MAUSS, Marcel

1903 "De quelques formes primitives de classification: contribution à l'ètude des représentations collectives", Année Sociologique, vol. VI (1901-2): 1-72.

EDELMAN, Marc; HAUGERUD, Angelique (Eds.)

2005 The Anthropology of Development and Globalization. Malden: Blackwell.

El Picot Negre. Revista Informativa del Parc Natural del Cadí-Moixeró.

2003 "El parc promou un itinerari entre vuit refugis de muntanya". 1: 5.

2004 "Presència del llop al parc natural". 3: 3.

ESCOBAR, Arturo

1999 "After Nature: Steps to an antiessentialist political ecology. Current Anthropology, 40: 1-30.

FERGUSON, James

2002 "Globlal Disconnect: Abjection and the Aftermath of Modernism", en Jonathan X. Inda; Renato Rosaldo (eds.) The Anthropology of Globalization. A Reader. Malden: Blackwell, 136-153.

FRIGOLÉ, Joan

2005 Dones que anaven pel món.Estudi etnogràfic de les trementinaires de la vall de la Vansa i Tuixent. Barcelona: Generalitat de Catalunya.

2006 "Globalización y producción de localidad en un valle del Alt Urgell", en J. Frigolé; X. Roigé (eds.), Globalización y localidad. Perspectiva etnográfica. Barcelona: Publicacions de la Universitat de Barcelona, 17-32.

2010 "Rusticity, Wild Flora and Fauna Patterns, and Identity in a Valley of Cadí (Alt Urgell), en I. Vaccaro; O. Beltran (eds.), Social And Ecological History Of The Pyrenees, State, Market, and Landscape. Walnut Creek, CA: Left Coast Press, 163-177.

2010a "Patrimonialization and the Mercantilization of the Authentic. Two Fundamental Strategies in a Tertiary Economy", en X. Roigé; J. Frigolé (eds.), Contructing Cultural and Natural Heritage. Parks, Museums and Rural Heritage. Girona: ICRPC, 27-38. 
GARCÍA PETIT, Jordi

2004 "Editorial". El Picot Negre 3: 2.

2004 "El llop". El Picot Negre 4: 9-11.

GARCÍA PETIT, Jordi; ALCÁNTARA GUIRADO, Carme

2008 "El vínculo social y natural como impulsor de la protección". Quercus, Suplemento Especial Catalunya, 272: 4-8.

GROUSSET, Véronique

2009 "Espèces menacées. Un crocodile au secours des crocos". Le Figaro Magazine, 5 de diciembre, 66-68.

HADJIMICHALIS, Costis; PAPAMICHOS, Nicos

1990“Local" Development in Southern Europe: Towards a New Mythology”. Antipode, 22, 3: $181-210$.

HEYMAN, Josiah

2004 "Conclusion: Understandings Matter". en J. Carrier (ed.), Confronting Environments. Local Understanding in A Globalizing World. Walnut Creek: AltaMira Press, 183-195.

JOHANSEN, Bruce; MAESTAS, Roberto

1982 Wasi'chu. El genocidio de los primeros norteamericanos. México: Fondo de Cultura Económica.

KIRSHENBLATT-GIMBLETT, Barbara

2001 "La cultura de les destinacions: teoritzar el patrimoni". Revista d'Etnologia de Catalunya 19: 44-61.

LEFEUVRE, Jean-Claude

1990 "De la protection de la nature a la gestion du patrimoine naturel”, en H. Jeudy (ed.), Patrimoines en follie. Paris: Maison des Sciences de l'Homme, 29-75.

MACDONALD, Kenneth

2004 "Developing "Nature": Global Ecology and the Politics of Conservation in Northern Pakistan" en J. Carrier (ed.), Confronting Environments. Local Understanding in a Globalizing World. Walnut Creek: AltaMira Press, 71-96.

MAUZ, Isabelle

2006 "Introductions, réintroductions: des convergences, par delà les différences". Natures Sciences Sociétés 14: 3-10.

PARDINILLA, Jordi

2006 "Joan Adam Vilalta, guarda major de la Reserva Nacional de Caça del Cadí". El Picot Negre. Revista Informativa del Parc Natural del Cadí-Moixeró 7: 22-23.

2008 "Joan Pubill, exalcalde de Cava: "Caldria que es valorés molt més la feina de pagès". El Picot Negre. Revista informativa del Parc natural del Cadí-Moixeró, 12: 26-27. 
RIVAS, Rosa

2010 "Ponga un jardín en su plato. Madrid Fusión dedica una jornada a la vanguardia de la "ecococina”. El País, 28 de enero, p. 42

RODRÍGUEZ, José

2011 "Redzepi. El señor de los fogones”, El País Semanal, no 1827, 2 de octubre, pp. $32-43$.

$\mathrm{S} / \mathrm{A}$

2010 “Jaime Rojo, director de Conservación de Agrupación Sierra Madre”. Escala, 20, pp. 82-83.

SALGADO, Gema

2010 "10 claves para vivir mejor. Sentir la naturaleza", Revista Cuerpo y Mente, 213: 36-37.

SÁNCHEZ-SILVA, Carmen.

2009 "Almuerzo con...María Eugenia Girón: El consumidor nos empuja hacia el lujo sostenible". El País, 31 de enero, contraportada.

STACUL, Jaro

2003 The Bounded Field. Localism and Local Identity in an Italian Alpine Valley. New York: Berghahn Books.

VACCARO, Ismael; BELTRÁN, Oriol

2010 "Un zoo en los Pirineos. Paradojas de la patrimonialización de la naturaleza" en C. del Mármol; J. Frigolé; S. Narotzky (eds.) Los lindes del patrimonio. Consumo y valores del pasado. Barcelona: Icaria, 169-189.

WATTS, Michael

1992 "Space for Everything (A Commentary)". Cultural Anthropology 7: 1.

VÁZQUEZ, Karelia

2009 “Guardianes de la lana”. El País Semanal, n. 1694, 15 de marzo, pp. 92-96.

WOLF, Eric

1982 Europe and the People without History. Berkeley: University of California Press.

1990 "Distinguished Lecture: Facing Power-Old Insights, New Questions". American Anthropologist 92: 586-596.

WOLFE, Patrick

1999 Settler Colonialism and the Transformation of Anthropology. The Politics and Poetics of an Ethnographic Event. London: Casell. 